\title{
Skeletal scintigraphy for a patient with a hip fracture
}

\author{
I. A. Siddiqui ${ }^{1}$ (D) R. Botchu ${ }^{2} \cdot$ S. K. Dalavaye ${ }^{1} \cdot$ A. Iqbal $^{1}$
}

Received: 14 October 2020 / Revised: 17 November 2020 / Accepted: 29 November 2020 / Published online: 7 January 2021

(C) ISS 2021

An 85 year old female patient with known locally advanced adenocarcinoma of the lung of mucinous sub-type sustains a traumatic proximal femoral fracture following a low energy fall and undergoes hip hemiarthroplasty. Her past medical history included a previous left deep vein thrombosis and hypertension. She is further investigated with an isotope study for metastatic disease 24 hours after surgery (Figs. 1, 2 and 3).

The diagnosis can be found at https://doi.org/10.1007/s00256-02003690-8.

\section{A. Siddiqui}

imran.siddiqui@wales.nhs.uk

1 Department of Musculoskeletal Radiology, Swansea Bay University Health Board, Morriston Hospital, Swansea, UK

2 Department of Musculoskeletal Radiology, Royal Orthopaedic Hospital, Birmingham, UK

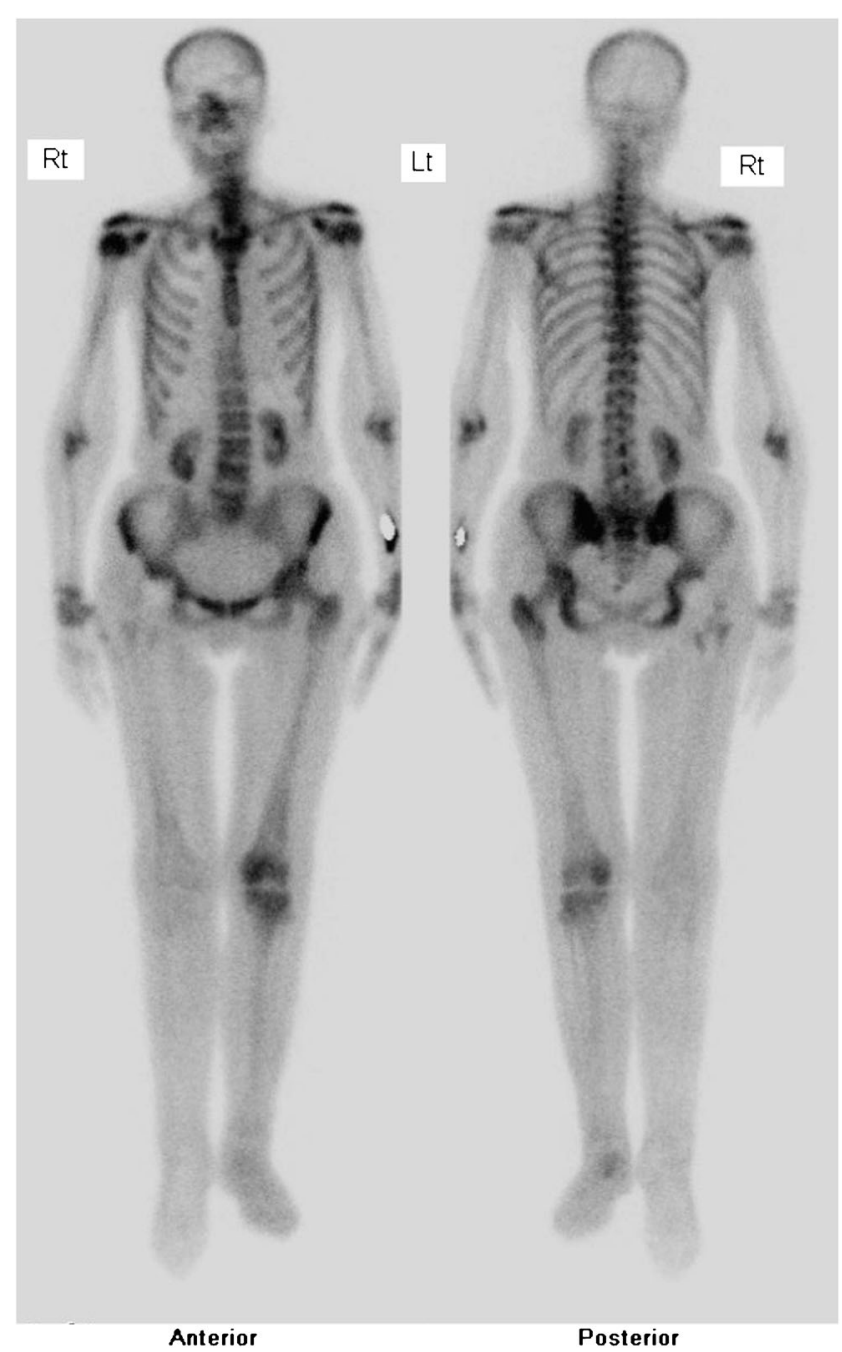

Fig. 1 Technetium-99 m hydroxymethylene diphosphonate (HMDP) 2 h whole body scintigraphy 
Fig. 2 a Pelvic radiograph; b right hip radiograph

Fig. 3 Axial CT scan with bone [C:500 W:2500] and soft tissue [C:70 W:500] windowing of the (a, b) proximal and (c, d) distal lower limb
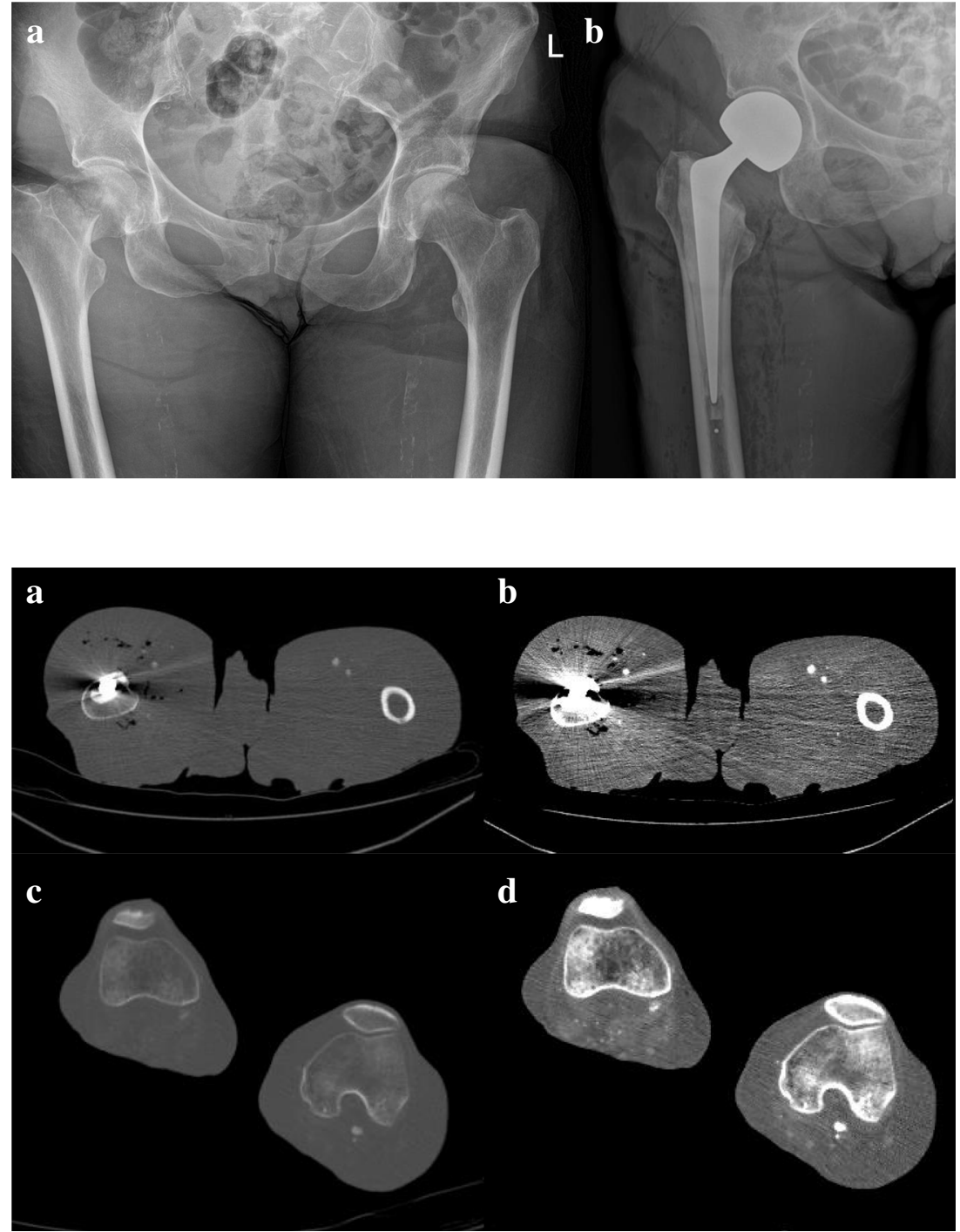

\section{Compliance with ethical standards}

Conflict of interest The authors declare that they have no conflict of interest.
Publisher's note Springer Nature remains neutral with regard to jurisdictional claims in published maps and institutional affiliations. 